\title{
Review of Ancient Greek Sculpture Color
}

\author{
Kuang Wang \\ School of Art \\ Nantong University \\ Nantong, China 226007
}

\begin{abstract}
Based on the emergence of primary color sculptures and the misunderstandings of ancient Greek sculptures, the Western Renaissance has formed a classical sculpture interest aesthetic in formal beauty and texture beauty. Archaeological studies confirmed that ancient Greek sculptures were once painted with colors, but only because of history and nature the color of the sculpture surface disappeared. Recalling the social, cultural and natural geographical backgrounds of the ancient Greek period, based on the creative purposes and material analysis of various types of ancient Greek sculptures, we will re-recognize the ancient Greek sculptures from the perspective of color and make a brief classification of the language features and manifestations of their colors to grasp the aesthetic appeal of ancient Greek sculpture macroscopically.
\end{abstract}

\section{Keywords-Ancient Greece; sculpture; color}

\section{INTRODUCTION}

The famous art historian of the eighteenth century, Winklman once described the ancient Greek art as "the noble simplicity and quiet greatness" and he also considered the supreme ideal of classical art. This assertion is based on the aesthetic beauty and material beauty of classical sculpture, but it ignored the color factor. A large amount of research shows that the vast majority of ancient Greek sculptures and architectural appearances have been painted with vivid colors, but due to prolonged weathering and rain erosion, the color on surface have disappeared. Not only ancient Greek sculptures, the ancient sculptures of many nationalities in the world are depicted with colors, which are a very common phenomenon, such as the Terra-Cotta Warriors in Qin and Han dynasty of China, Figure sculpture of Egypt and the mausoleum sculptures of India. Ancient Greece, as the source of the entire European art civilization, the color language of classical sculpture in the ancient Greek period and the region at that time presented different patterns. In the ancient Greek cultural context, the color language conveys more than just a variety of visual sensations. Its connection with social life reflects Western classical aesthetic ideas and philosophical spirit.

From the perspective of the history nature of ancient Greek sculpture, the objective color depicting the real world enhances the artistic expression of the figure and the authenticity of the scene. It also better shapes the overall mental outlook of the sculpture. The high-level painting of ancient Greek for sculpture figure character supplemented by color coincides with the "carving the appearance and painting the essence" of Chinese traditional sculptures. In addition, there are subjective colors of the emotional expression for sculptures, mainly in the theme of mythology and religious sculptures, which aim to highlight the infection of indoctrination and expression of tension of internal divinity. Ancient Greek sculpture not only assumed the function of religious worship and urban beautification in the historical function of society, but also spiritually guided the people's life to the beautiful hope. The sculptures in the ancient Greek period were influenced by society, religion, and other aspects and showed various linguistic characteristics in its color. They also showed different forms of colors expression in the sculptural shapes and materials.

\section{II. "USING COLORS ACCORDING TO THE TYPES" IN ANCIENT GREEK SCULPTURE}

In the "Six Laws" put forward by Xie He in "Painting", he set the criteria of "using colors according to the types" for Chinese paintings. It mainly means that we can paint according to the objective color of objects, as well as use colors according to subjective wishes. The standard for choosing color lies in the determination of the classification of objects. From the perspective of the standards for evaluating Chinese ancient art and the important aesthetic principles, it can also be applied to the analysis of ancient Greek sculptures and other world fine arts. Starting from the classification of objects, ancient Greek sculptures can be roughly divided into five types: (1) gods for religious worship, such as Zeus, Athena, Aphrodite, etc.; (2) relief as the decoration of temple (3) Portraits of people in the world, such as statues of Kuros, Kola, and winners in sports competitions; (4) statues of animals for sacrifice; (5) funeral tomb sculptures. [1]

The first is the statue sculpture. Most of the ancient Greek sculptures are placed in special shrines. There are "numerous statues in the temple to commemorate the glorious deceased. They are made of marbled, gold, silver, brass bronze and other colors of other metals, gathering in twos and threes. Some are standing and others sitting, all shining, which is truly the deployment of god of light". ${ }^{1}$ There is also a statue of Athena in the Temple of Patr which is known to people. According to the restoration map of the study, the Athena goddess is covered with golden armor and clothing accessories, and the body skin is made of ivory with colored stones in eyes. The rest are depicted in bright colors.

See Michelle's Bible, pp. 205. - Original note 
[2] It is not difficult to find that the ancient Greeks mainly used the natural ore and valuable tributes to shape the colors of the statues, and the colors used in the rest were bright and attractive. In the context of religious worship, the color depictions of the statue of God are mostly subjective, aiming to express the reverence and respect of the ancient Greeks for gods to get shelter and blessing. The early Greek sculpture and architecture have an inseparable relationship. The representation of the building with the temple as the main style was naturally inseparable from the depiction of mythological themes. Therefore, it can be seen that apart from the use of precious stones and tributes, the color of decoration is likely to be in harmony with the statue of gods in the temple, which is the type of bright light. In addition to statues of gods, many secular characters are also topics that the ancient Greeks keen to make, such as the Calf and the Cora with the Water. These young men and women's statues are mainly the objective depictions of the believers themselves, which are used to pray for them in the temple, so the color of these types of sculptures is closer to the performance of the objective image, with less dazzling appearance of the statue. Although the colors of secular portraits are relatively simple compared with that of statue of god, the differences in the color of clothing between young men and women are still relatively large. Since women spend more time indoors, the skin of female statues adopts softer colors and the colors of women's clothing are bright. [3] The statues that are of the same type with secular youth are that of athletes. At the ancient Greek Games, the winners were mostly regarded as people who were blessed with divine and had divine power. They are respected by people, so the public will make a statue for the athletes who win in the game to commemorate them. For those who win three times, the statue of their portraits will be made. Their statues will be placed around the temple. [4] In general, the use of color in ancient Greek sculpture creations is basically differentiated according to function. The color of virtual portrait headed by the statue of gods is dominated by vivid subjective colors, while the colors of secular portraits are mostly the true color of objective images. Of course, the color depicted on the statue not only enhances the visual appearance of the sculpture, but also reflects the spiritual outlook of the entire sculpture and is full of religious appeal.

\section{The PENETRATION OF COLOR PracticAl Thoughts}

The use of color in classical sculpture was first for serving the utility. The early sculpture color depended on the natural color of the material itself. For example, the statue of Minerva discovered in the Roman Empire Square in the early 1st century is made of all kinds of different colored marbles. In ancient Greek period, a magnificent moment in the history of human art, the sculpture art reached an unprecedented height in the classical world and reflected the high degree of civilization in the ancient Greek period. In this period with advanced culture, sculptors have greater autonomy in the use of color. The use of each color is accompanied by the author's subjective purpose and objective natural geography and social and cultural requirements. They constitute the practical idea of sculpture color of ancient Greece.
From the analysis of natural geographical factors, the use of color in ancient Greek sculpture aims to weaken the reflection of marble. Ancient Greece is located in the southern part of Europe, the northeast of the Mediterranean Sea. The climate is a typical Mediterranean climate, where there is strong sunlight. Although marble itself does not require the protection and preservation of color patina, under the influence of such natural factors, it is almost impossible for people to appreciate the marble architecture and sculptures in the open air. Therefore, the marble temple represented by the Temple of Pytat is always treated with orange-yellow organic pigments to reduce the brightness of the over-white marble. The same method was also used on the statues of people in the open air, such as the "Kritien juvenile," which was created on the theme of athletes. The portrait's skin was painted in reddish brown under the sunlight, which reduced the bright color tone, but also objectively depicts the true skin color of a portrait.

From the perspective of social culture, on the one hand, the ancient Greek sculptures uses color to enhance the ornamental value. On the other hand, it can strengthen the spread of religious infections. People of the ancient Greek, with their wisdom, confidence and skill, vigorously developed economy and established a democratic system to push Greece to the pinnacle of world culture. At this time, the Greek people's aesthetic needs have also been continuously increasing. Therefore, more and more statues stand in Greek city-states. Saint Paul visited Greece in the 1 st century BC. He described it as "the forest of idols." It can be seen that there are many portraits made of marble, bronze and wood throughout Greece. In such a social state, the "publicity" of sculptures is highlighted. Unlike the classical sculptures now displayed in museums, the sculptures at that time were not just a quiet "artwork". The German-American art theorist Arnheim once said: "Sculptures cannot be regarded as an object that can be moved in the most complete sense, because they are related to the place that is influenced by their meaning and in turn determines their meaning. Therefore, it is not difficult to understand that the a large number of sculptures in the city-state use color to occupy an important position in the visual aesthetic experience of the Greeks when looking back on the production environment and exhibition way of ancient Greek sculptures. Visual enjoyment can be attributed to humanities, but the more important purpose of using colors in ancient Greek sculpture is to strengthen the power of religious communication. Sculpture has the characteristics of visualization and long-lasting reproducibility. The religions and ceremonies no matter when and where did not give up using sculpture media for the purpose of promoting education. For example, the large number of Buddhist sculptures in China cannot be shaken in the history of ancient sculptures, so it is the same in ancient Greece. The ancient Greek traveler, Pausanian, described in his book "The Guide of Greece" the scene of sacrifice in front of the temple and proposed the religious functionalism that the sculpture art of the gods plays in the activities of worshiping gods visually. Since the statue of god bears the practical function of religious worship and sacrifice, the shaping of color in the statue is indispensable. Placing a monochrome marble statue 
in the temple is not as convincing as a life-like and dazzling statue of the god. Even the relief on the external eaves of Parthenon that is more than 160 meters long and praises goddess parade must also use bright colors, not only to adapt to the overall tone of the temple, but also to express that the secular human beings are as great as gods. In short, the decorativeness of the ancient Greek sculpture as a visual art enhances the aesthetic function. As the object of worship for religious dissemination, the color strengthens the transmissibility of religion, and practical thoughts are thoroughly implemented in color.

\section{CONCLUSION}

Ancient Greek sculptures are divided to different types with the development of the cultural level, which have their own uses. Their materials and artistic styles make the sculpture color also show a diversity of formal characteristics. Since ancient Greece was far too long ago, influenced by history and natural factors, most of the authentic works of sculptures and buildings are no longer in existence. Therefore, it is difficult to define and categorize the colors of the sculpture accurately, and we can only infer based on the classical social background and natural state in ancient books and records. The misunderstanding of ancient Greek sculptures after the Renaissance gradually formed an aesthetic interest in the sculptures made by marble of primary color, which led us to overlook the glory that had existed in ancient Greek sculptures. Under the burial of time, they went from "warm" to "silent". As the British scholar William Gail said: "No nation has shown more enthusiasm than the Greeks for various bright colors." Although many things cannot be verified, whether it is the color of natural materials or the color of artificial hand-painting, and whether it is a solemn statue or a lively secular portrait or animal portrait, the ancient Greek sculpture has a rich color language and a high level of painting techniques, which can make us astonished as its accurate appearance.

\section{REFERENCES}

[1] Chang Ningsheng. From the Painted Sculpture to the Single-sculpture - A Historical Misunderstanding of the Aesthetic Interest of Ancient Sculpture[J]. Journal of Southeast University (Philosophy and Social Science),2003(5). 常宁生.从彩绘雕塑到单质雕塑——对古代雕塑 审美趣味的一种历史性误会 [J]. 东南大学学报 (哲学社会科学 版)，2003（5）.

[2] Wang Jiabin, Wang He. 100 masterpieces of world sculpture [M]. Tianjin: Baihua Literature and Art Publishing House, 2006:31-33. 王 家斌, 王鹤. 世界雕塑名作 100 讲[M].天津: 百花文艺出版社, 2006: 31-33.

[3] Nigel Spivey, Understanding Greek Sculpture : Ancient meanings, Modern Readings[M] . Thames and Hudson Ltd, London 1997: 77.

[4] [French]Dana. Philosophy of Art [M].Fu Lei,Tr. Nanjing: Jiangsu Literature and Art Publishing House,2011:51. [法]丹纳.艺术哲学[M]. 傅雷, 译.南京: 江苏文艺出版社, 2011：51. 